\title{
Detecting Slums from SPOT Data in Casablanca Morocco Using an Object Based Approach
}

\author{
Hassan Rhinane $^{{ }^{*}}$, Atika Hilali ${ }^{1}$, Aziza Berrada ${ }^{1}$, Mustapha Hakdaoui $^{2}$ \\ ${ }^{1}$ Faculté des Sciences Ä̈n Chock, Université Hassan II-Casablanca, Casablanca, Maroc \\ ${ }^{2}$ Faculté des Sciences Ben M'sik, Université Hassan II-Mohammedia-Casablanca, Casablanca, Maroc \\ E-mail:h.rhinane@gmail.com,a.hilali@fsac.ac.ma,berrada_aziza@yahoo.fr,hakdaoui@gmail.com \\ Received April 2, 2011; revised May 23, 2011; accepted June 5, 2011
}

\begin{abstract}
Casablanca, Morocco's economic capital continues today to fight against the proliferation of informal settlements affecting its urban fabric illustrated especially by the slums. Actually Casablanca represents $25 \%$ of the total slums of Morocco [1]. These are the habitats of all deprived of healthy sanitary conditions and judged precarious from the perspective humanitarian and below the acceptable. The majority of the inhabitants of these slums are from the rural exodus with insufficient income to meet the basic needs of daily life. Faced with this situation and to eradicate these habitats, the Moroccan government has launched since 2004 an entire program to create cities without slums (C.W.S.) to resettle or relocate families. Indeed the process control and monitoring of this program requires first identifying and detecting spatial habitats. To achieve these tasks, conventional methods such as information gathering, mapping, use of databases and statistics often have shown their limits and are sometimes outdated. It is within this framework and that of the great German Morocco project "Urban agriculture as an integrative factor of development that fits our project detection of slums in Casablanca. The use of satellite imagery, particularly the HSR, has the advantage of providing the physical coverage of urban land but it raises the difficulty of choosing the appropriate method to apply.This paper is actually to develop new approaches based mainly on object-oriented classification of high spatial resolution satellite images for the detection of slums.This approach has been developed for mapping the urban land through by integration of several types of information (spectral, spatial, contextual ...) (Hofmann, P ., 2001, Herold et al. 2002b; Van Der Sande et al., 2003, Benz et al., 2004, Nobrega et al., 2006). In order to refine the result of classification, we applied mathematical morphology and in particular the closing filter. The data from this classification (binary image), which then will be used in a spatial database (ArcGIS).
\end{abstract}

Keywords: Slums, Urban Remote Sensing, SPOT 5, Object Based Image Analysis, ArcGis

\section{Introduction}

The study by the World Bank [1] showed that Casablanca has the largest population of slums with approximately 45,000 households located in 270 nuclei, or a quarter of the total national population of urban slums. This type of habitat is populated by the most impoverished social strata, not complying with the Building Standards (illegal or non-regulatory), with a low or absent infrastructure and no security measure [2]. Often these habitats are covered with recycled materials (sheets, plastics, wood ...) and organized as clusters of strong condensation of several informal settlements. Some neighbourhoods such as Hay Mohammadi, Ben M’sik, Sidi Moumen has always housed the largest concentrations of slums and even wealthy neighbourhoods as Anfa, Ain Diab, Racine, California have their own islands of poverty so that it becomes excessive to conclude to a real structure of spatial segregation [3]. View the restriction of traditional methods employed (field visits/observation) and the unknown dynamic of the metropolitan population [4], the Moroccan government adopted in January 2005, a new innovative approach to monitor and map the slums through remote sensing (aerial photographs, satellite imagery ...) in some pilot cities.

Certainly, satellite imagery has shown several ad- 
vances in extraction of different urban entities providing timely and accurate responses to the occupation of urban land. However, very few studies have focused on mapping slums in urban areas [2,5-10] but their application in urban North Africa today remains marginal or even absent.

The objective of this work is to extract, identify and map these slums in the city of Casablanca in 2004 through an object-oriented classification of a SPOT-5 at $2.5 \mathrm{~m}$ spatial resolution.

\section{Material and Methods}

\subsection{Location of the Study}

Morocco's economic capital and one of the largest cities in the continent, Casablanca is the largest city in Morocco with more than 3 million inhabitants with a total area of 1,140.54 $\mathrm{km}^{2}$ [1] (Figure 1). Casablanca is located on the Atlantic coast about $100 \mathrm{~km}$ south of the administrative capital (Rabat). The Wilaya of Greater Casablanca includes two prefectures (Mohammedia \& Casablanca) and two Provinces (Nouaceur or Nouasser and Mediouna) for a total of 17 municipalities, 10 urban and seven rural communities.

\subsection{Available Data and Preprocessing}

Satellite images become now an essential tool for plan- ning and land development due to the frequency of shots and the spatial resolution more and more efficient. The launch of satellites with high spatial resolution (HSR), such as SPOT-5 (2002) with $10 \mathrm{~m}$ spatial resolution multi-spectral mode and $5 \mathrm{~m}$ spatial resolution in panchromatic mode, allowed the extraction of different urban entities. The main data used in this work are:

- Image of SPOT-5 Casablanca taken March 16, 2004, georeferenced, orthorectified and merged with $2.5 \mathrm{~m}$ spatial resolution. This picture was taken during a sunny month which helped the contrast between different urban entities. To improve the visual quality of this picture we have carried image enhancement and filtering operations (Figure 2).

- Cards Master of Urban Planning of the Wilaya of Greater Casablanca provided by the Urban Agency of Casablanca used to validate.

- Topographic map of the city of Casablanca, (NI-29sheet XI-3B) wide 1/50000 used for tracking in the field and for areas difficult to access. The images of Google Earth Server Map and Google Map have been very useful.

The satellite data processing was performed on Erdas Imagine then Envi Zoom. The classification results were vectorized and exported to ArcGIS.

\subsection{Methodological Approach}

The study of the urban fabric has always interested

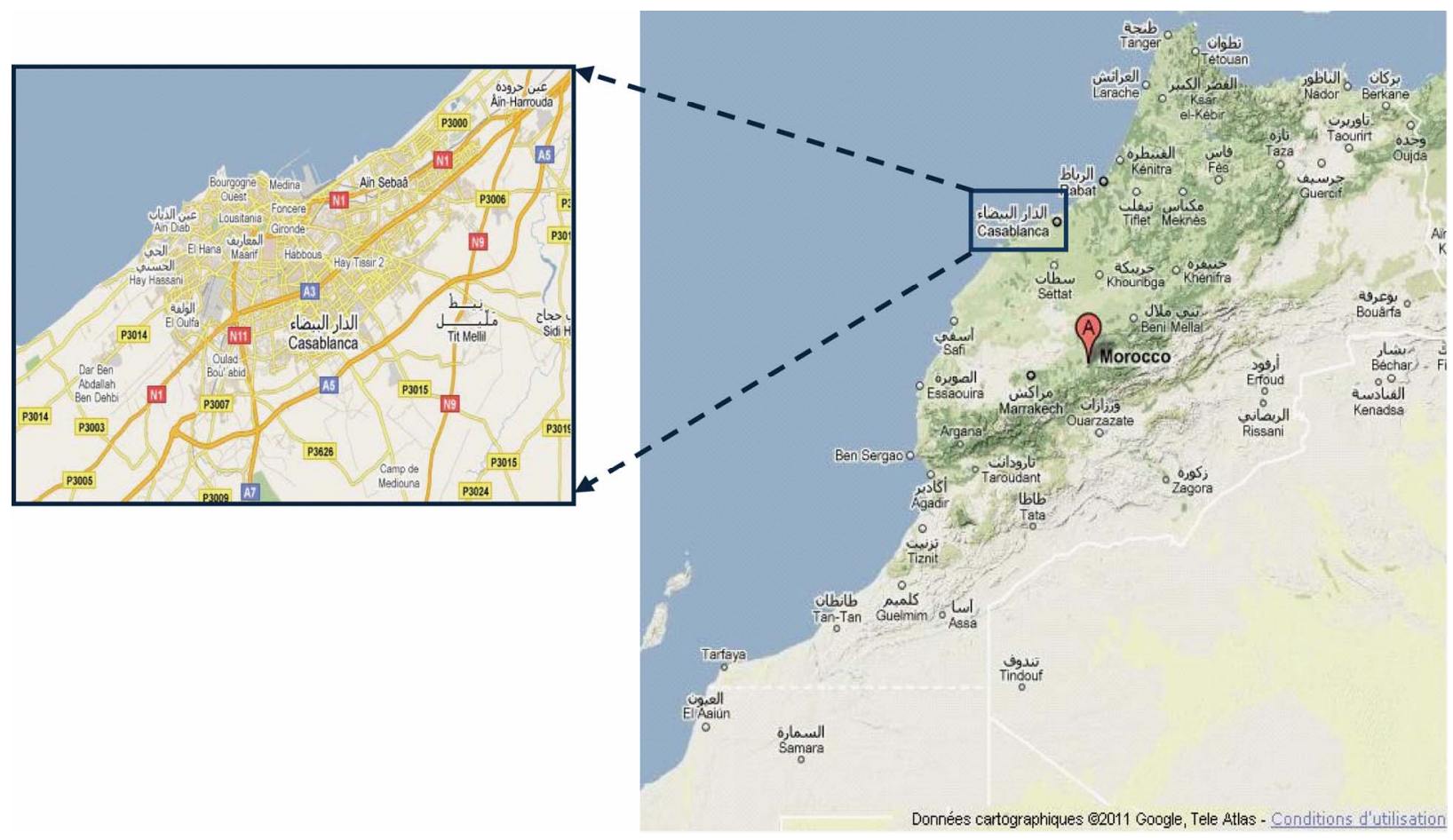

Figure 1. Geographical location of the city of Casablanca. 

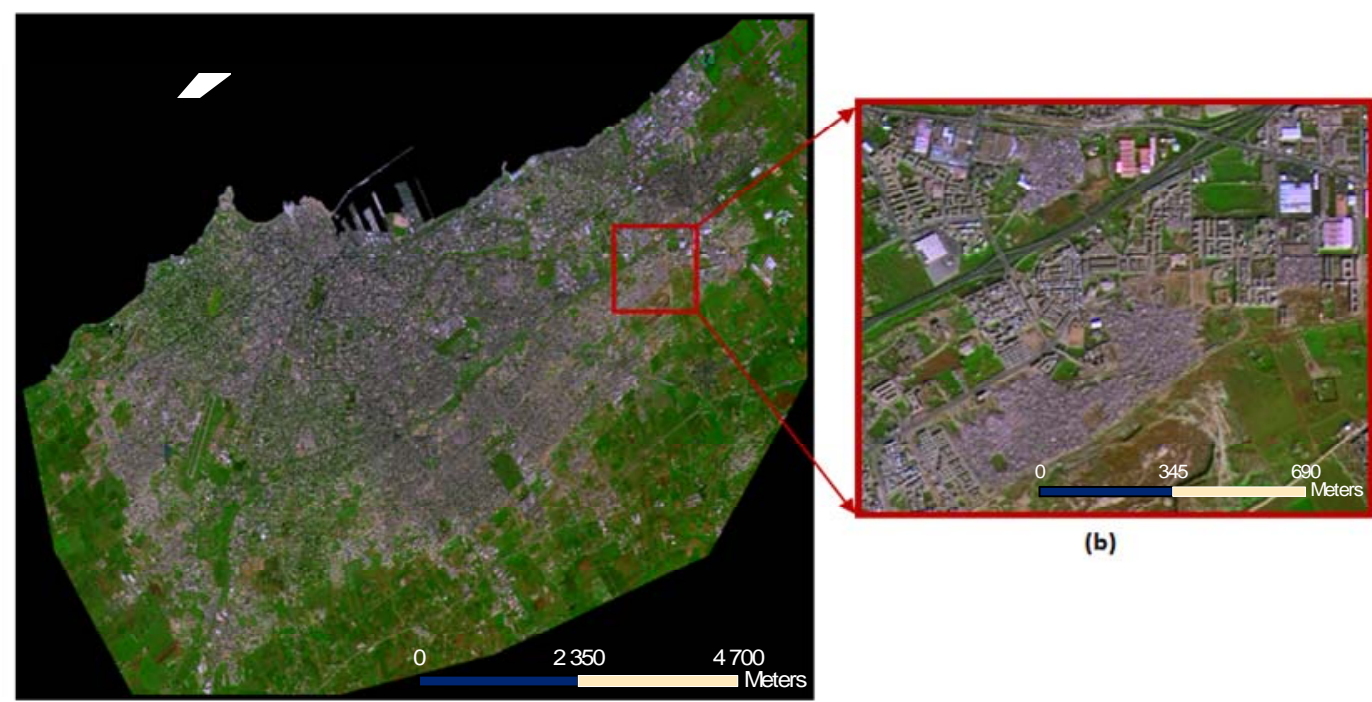

(b)

(a)

Figure 2. (a) merged Image SPOT-5 of the city of Casablanca; (b) Overview of slums on image SOPT-5 of Casablanca.

several researchers in management and urban planning. The use of satellite imagery has the advantage of providing the physical coverage of urban land but it raises the difficulty of choosing the appropriate method to apply. Several pattern recognition algorithms are used in urban areas on images HSR: the urban morphology [11-15], INDVI [16], the image thresholding [17], neural networks [18,19], semi-automatic procedure [20], Digital Elevation Model [21], yet the object - oriented approach $[22,23]$, the index of landscape [10], clustering and geographic information system [24,25].

Choosing one method over another is not easy and depends on data availability and purpose of the study. In the context of detecting the slums, some studies have used aerial photographs [7], others a semi automatic [20] or supervised classification by maximum likelihood [10]. Also, urban space, by its very heterogeneous nature, becomes more complex to study by the presence in soil of many objects different by their shape, direction, size, material depending on the type of habitat [2] and this in addition to the constraints inherent to the pixel size (2.5 m) [10]. The combination of the texture will certainly improve the quality of classification [26-28] and will make easier the identification of the slums among other objects with similarities and which can lead to confusion in interpretation (built dense, unhealthy habitat, roof...).

Since decades, the approach classification “object oriented" has been developed for mapping the urban land through the integration of several types of information (spectral, spatial, contextual ...) [6,23,29-31] hence its adoption for this project. Figure 3 illustrates the methodology adopted in this work to map the slums of Casablanca.

\subsection{Object-Oriented Classification}

The object-oriented classification in ENVI is an iterative process carried out in two stages:

- Segmentation: sequence of several steps of segment-

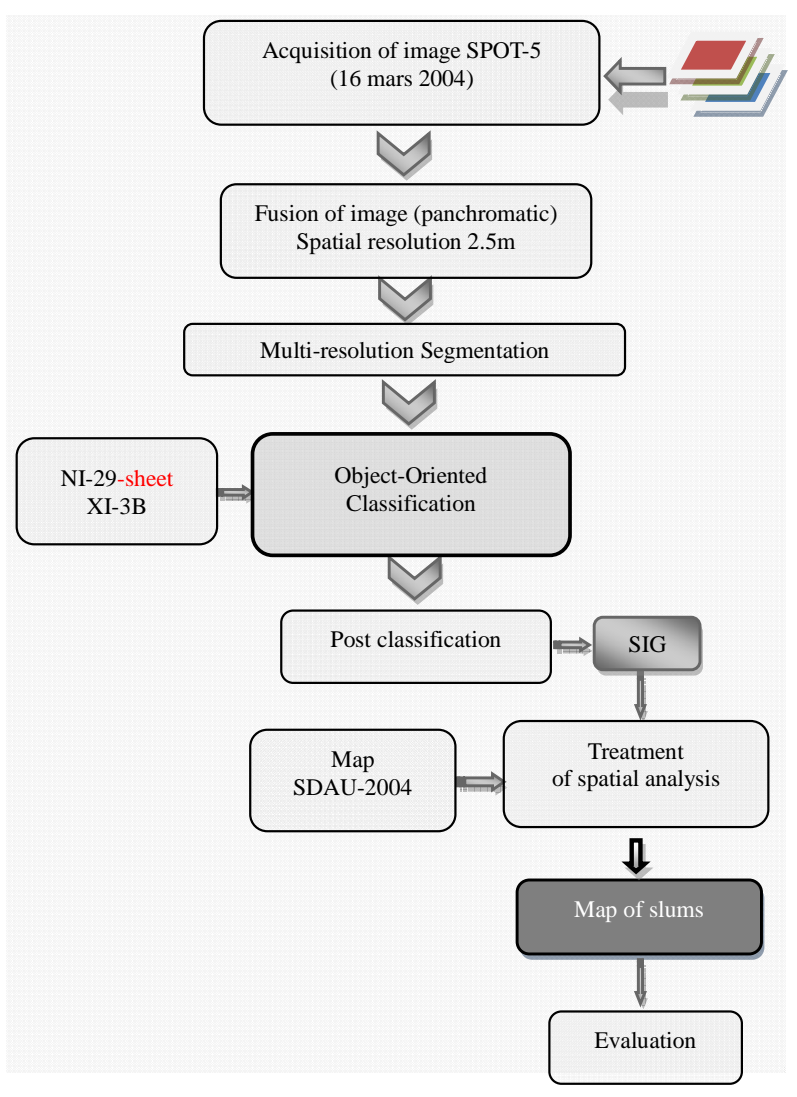

Figure 3. Methodological flowchart. 
ing the image into regions.

- Supervised classification.

\subsubsection{Segmentation}

It consists to subdivide the image in the visible range, in homogeneous regions, taking into account the spectral parameters (mean, standard deviation index calculation), space (size, shape) and contextual (spatial relationships between regions) [32-35]. During this process, segments are created by fusion of adjacent pixels forming sub objects that will be gradually merged with their neighbors to create objects of sizes larger and larger with similar forms well distributed in the urban space according to a scale parameter (or criterion of heterogeneity) defined by the user. The objects thus created are linked together by a hierarchical network representing the reality on the field [28-36] (Figure 4). This parameter, also called "weight" determines the segmentation process and therefore the size of the segmented objects. The higher this parameter is, the higher the items are of larger size. These parameters were set at 30 for level 1 and 93.3 for level 2.

\subsubsection{Classification of the Image SPOT-5}

After segmentation, the second step is to group objects and assign them a probability or degree of belonging to a given class from the robust rules of recognition of the regions. Several knowledge rules can be combined to define the classification rule of a given object, corresponding to the method of "nearest neighbors", or the method of "membership functions (fuzzy logic) or a mixture of two [37].

Supervised classification in ENVI Feature Extraction is an iterative process from the "nearest neighbor" algorithm based on K-nearest neighbor. The advantage of the approach "nearest neighbor" is that classes are

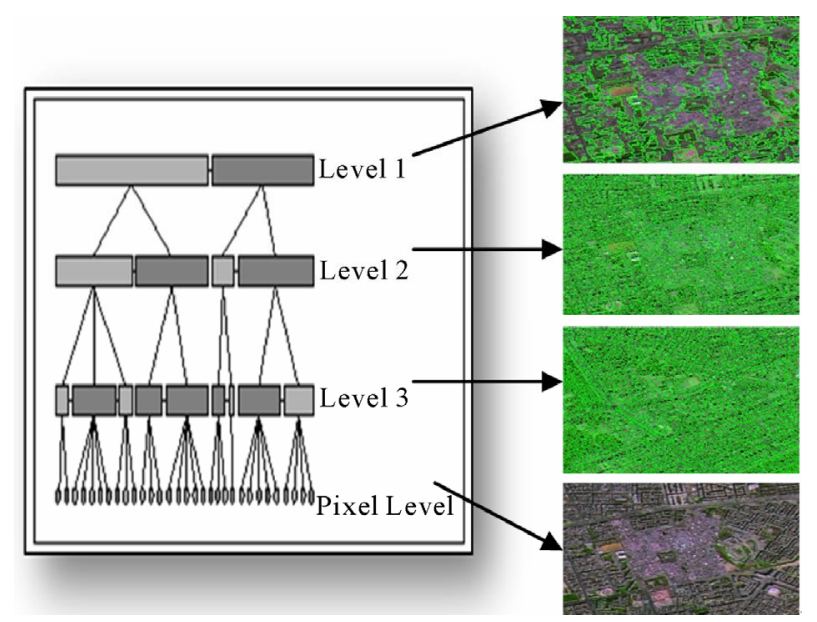

Figure 4. Principle of multi-resolution segmentation modified of [38]. defined based on a variety of attributes spatial, spectral and textural and is dependent on the choice of training sites.

The choice of training sites was an important step in the classification process adopted. These training sites were chosen carefully for they are as representative as possible of the class slums. However, due to the strong heterogeneity of the urban environment and the complexity of the objects to be extracted, the result of objectoriented classification of SPOT-5 image shows the presence of bad pixels assigned to predefined themes giving a salt-effect pepper.

Certainly, the best classification results are closely related to the choice of training sites and in order to define the different thematic classes we performed an unsupervised classification based primarily on spectral signatures. Roughly, two classes are distinct urban image SPOT-5 (Frames, vegetation (dense and grass)). Thus a wide range, the most representative samples were collected for major urban classes (vegetation, built and slums). The result of this classification is a binary image (slums/No-slums).

\subsubsection{Validation of the Classification}

The evaluation of a classification is a complex concept that includes the reference to several criteria that can occur in several stages [39]. The main idea is to determine the accuracy of this classification by comparing the results with data provided from the reality in the field. These realities comes from Master Plan (Department of Urban Planning of the Wilaya of Greater Casablanca [40] provided by the urban agency in Casablanca and physical verification.

In general, the classification evaluation is done by calculating two indices from the confusion matrix: overall accuracy and Kappa index. The Kappa index indicates how to classify the data agree with reference data $[41,42]$ Given that the main theme of this study focuses on one topic or class slums, the evaluation of this classification will be calculated manually empirically using the geographic information system (ArcGIS) and this by calculating commission and omissions errors on this class.

\section{Results and Discussions}

The choice of training sites was an important step in the classification process adopted. These training sites were chosen carefully for they are as representative as possible of the class slums. However, due to the strong heterogeneity of the urban environment and the complexity of the objects to be extracted, the result of object-oriented classification of SPOT-5 image shows the presence of bad 
pixels assigned to predefined themes giving a salt-effect pepper. The result of the classification (binary image) is then exported to ArcGIS, mapping of slums in the city of Casablanca is achieved.

In order to remove misclassified pixels and to refine the result of classification, we applied mathematical morphology and in particular the closing (succession of dilation and erosion). The tests showed that the window of the structuring element for better results is that of $9 * 9$ (Figure 5).

After the classification and the passage of the filter (closing), evaluation of results was done according to quantitative (number of slums correctly present in the SDAU, 2004; errors of commission and omission) and qualitative methods (form, difference between slums and informal settlement...). The overlay map slums (SDAU) in 2004, provided by the urban agency in Casablanca, on the map after the object-oriented classification of the SPOT-5 shows that 64 of 75 slums have been properly classified and 29 items were incorrectly assigned to this class. Thus, the commission error is $29 * 100 / 93=31 \%$ and omission error is $11 * 100 / 64=17 \%$, precision user $(\mathrm{Pu})$ is $64 * 100 / 93=69 \%$ and the accuracy of producer (Pi) is $64 * 100 / 75=85 \%$. We assume that the precision obtained through the classification of object-oriented image SPOT-5 is quite high.

Knowing the heterogeneity and complexity of the spectral coverage of urban land, and for the spatial resolution of the image used, some objects appear to have similarities (show and textural) with slums which implies their assignment to this class. Analysis of urban objects committed to the class slums shows some visual similarity between them because of their shape and their spectral signature (Figures 6 and 7) these objects are either slums, densely built or in some cases bare soil.

On slums that were omitted from the classification are primarily small sizes averaging $3800 \mathrm{~m}^{2}$ or 240 pixels,

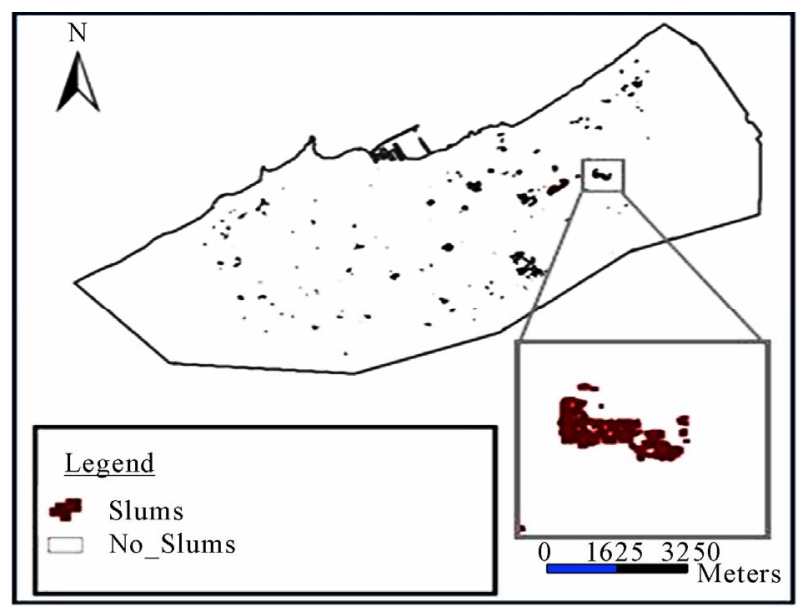

Figure 5. Image SPOT-5 classified.

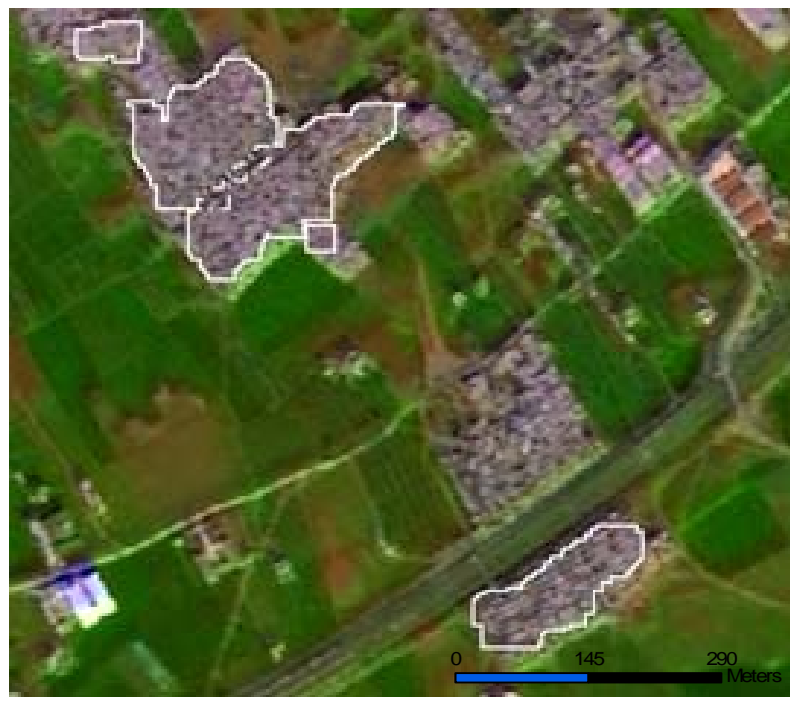

Figure 6. Section of the SPOT-5 image of the city of Casablanca showing habitats unhealthy (white) assigned to the class of slum.

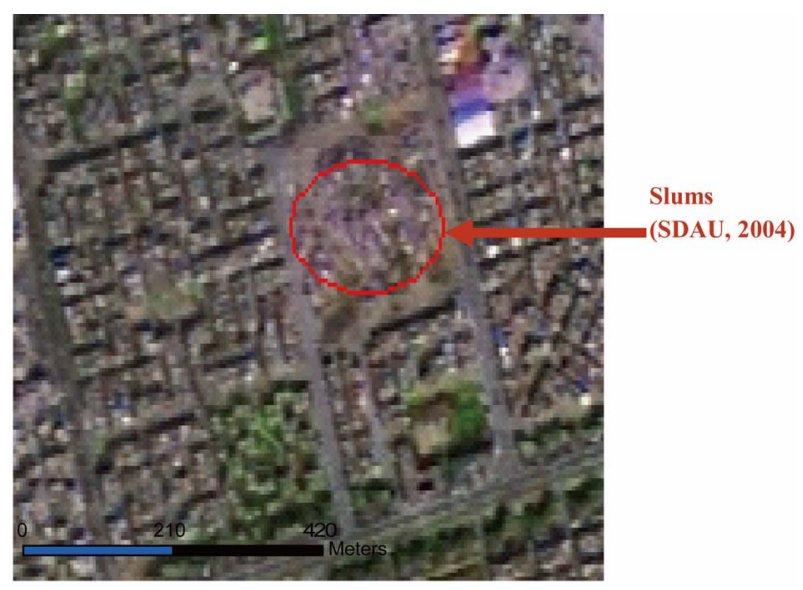

Figure 7. Section of the SPOT-5 in the Casablanca slums showing (red) unclassified.

these clusters are isolated rather than clustered buildings. Also, these slums have different spectral responses from those of all slums and who were chosen as training site (Figure 8).

\section{Conclusions}

Through this study, we demonstrated the importance of using satellite images with high spatial resolution SPOT-5 in particular the identification and quantification of these slums in the city of Casablanca. We also showed that object-oriented classification approach has proven remarkably effective for the extraction of slums (85\%). This result is satisfactory and fulfills our stated objective. It also confirms the relevance of the image to SPOT5 2.5 $\mathrm{m}$ spatial resolution to discriminate the class slums pre- 


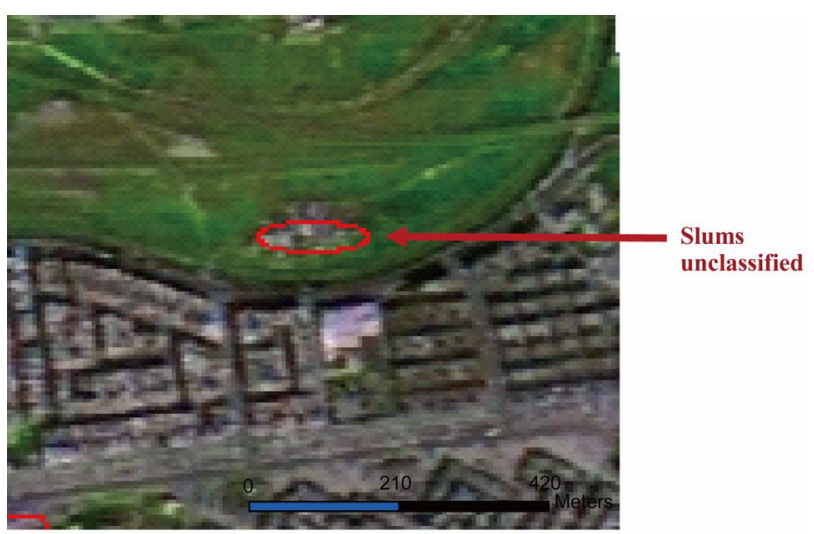

(a)

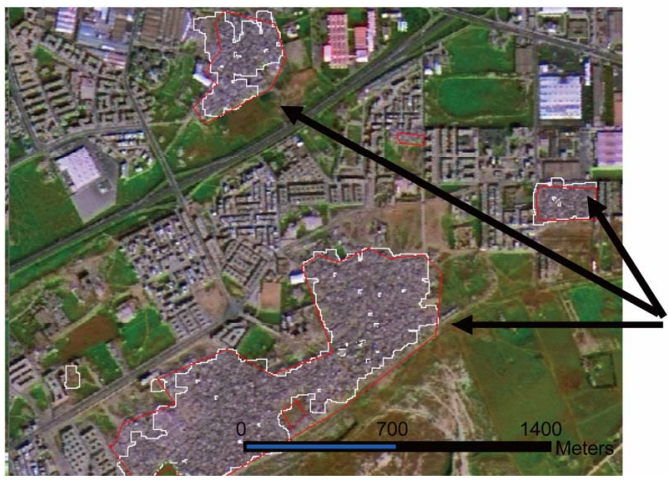

Slums classified

(b)

Figure 8. Sections of the SPOT-5 with slums unclassified.

ssent in a heterogeneous environment such as urban areas.

Even if the result obtained using the "feature extraction” ENVI Zoom gives reliable results, but it nevertheless remains limited. This limitation is due to the fact that some urban classes with a high spectral and textural similarity may be confused and will diminish the quality of the classification where the complexity of extracting the urban class.

This research may provide a basis for more advanced work on the implementation of a map of urban settlement where we can distinguish between different urban entities. Thus, the map after this classification will be used as a basis for establishing a spatial vector database of the slums of the city of Casablanca. Another approach based on an analysis of the diachronic evolution of the class of slums can also be the subject of new research or even an estimate of the urban slum [43].To do so would require several images taken at different times as this will also identify the slums but also to assess the rate of progression and use of satellite images of higher resolution will be an asset (eg IKONOS 1m spatial resolution).

\section{References}

[1] Banque mondial, “Rapport de L'Analyse D’lmpact Social et Sur la Pauvreté,” 2006, p. 62.

[2] K. Busgeeth, J. Whisken and A. Brits, "Potential Application of Remote Sensing in Monitoring Informal Settlements in Developing Countries Where Complimentary Data Does Not Exist," Planning Africa ConferenceShaping the Future, Johannesburg, 4-16 April 2008, pp. 314-328.

[3] M. Laoudi, "Casablanca a travers ses petits entrepreneurs de lapauvrté. Apprécu sur les micro-activités marchandes de rue dans une métropole maghrébine. Série thèse et mémoire N 8. Université Hassan II Aîn Chock, Faculté des lettres et sciences humaines Casablanca, 2001, p. 319, 320.

[4] S. Gadal, "Urbanisation et Dynamiques de Peuplements: Casablanca, 1994-2002, UMR 63 IRD-UVSQ,” Versailles Saint-Quentin-en-Yvelines University, Ver- sailles, 2005.

[5] S. Mason, C. Fraser, "Image Sources For Informal Settlement Management," Photogrammetric Record, Vol. 16, No. 92, 1998, pp. 313-330.

[6] P. Hofmann, "Detecting Informal Settlements from IKONOS Image Data Using Methods of Object Oriented Image Analysis: An Example from Cape Town, South Africa,” In: C. Jrgens, Ed., Remote Sensing of Urban Areas, Regensburger Geographische Schriften, Regensburg, 2001, pp. 107-118.

[7] P. Hurskainen and P. Pellikka, "Change Detection Of Informal Settlements Using Multi-Temporal Aerial Photographs-The Case of Voi, SE-Kenya," Proceedings of the 5th AARSE Conference, 18-21 October 2004, Nairobi, pp. .

[8] T. Lemma, “A Comparison of Methodologies for Monitoring Slum Conditions within Millennium Development Goals, the Case Study of Addis ababa, Ethiopia, Thesis for Master," International Institute for Geo-information Scinces and Earth Observation, Enschde, 2005.

[9] P. Hofmann, J. Strobl, T. Blaschke and H. Kux, "Detecting Informal Settlements from Quickbird Data in Rio de Janeiro Using an Object Based Approach,” Accessed 25 September 2007.

[10] G. Skupinski, D. BinhTran and C. Weber, (2009). "Lesimages Satellites Spot Multi-Dates et la Métrique Spatiale dans L'etude du Changement Urbain Et Suburbain-Le Cas de la Basse Vallée de la Bruche (Bas-Rhin, France)," Cybergeo: European Journal of Geography, Systèmes, Modélisation, Géostatistiques, article 439, mis en ligne le 12 mars 2009, modifié le 03 juin 2009. http://cybergeo.revues.org/index21995.html.

[11] W. K. Pratt, "Digital Image Processing," Willey inter-sciences, New York, 1978, p. 743. M. Robin, "La télédétection,” Nathan, Paris, 1995, p. 318

[12] Y. Baudot, “Télédétection Aérospatiale et Analyse Géographique de la Population des Villes dans les Pays en Développement,” Thèse de doctorat, Université Catho- 
lique de Louvain, Louvain-la-Neuve, 1994.

[13] P. Terrettaz "Délimitation des agglomérations et segmentation urbaine à l'aide d'images satellites Spot HRV," Thèse de Doctorat, Université de Fribourg, Fribourg, 1998.

[14] J. A. Benediktsson, M. Pesaresi and K. Amason, "Classification and Feature Extraction for Remote Sensing Images From Urban Areas Based on Morphological Transformations," IEEE Transactions on Geoscience and Remote Sensing, Vol. 41, No. 9, 2003, pp. 1940-1949.

[15] D. Sheeren, S. Lefèvre and J. Weber, "La MorphoLogiemathématique Binaire Pour L'extraction Automatique des Bâtiments dans les Images THRS,” Revue Internationale de Géomatique, Vol. 17, No. 3-4, 2007, pp. 333-352.

[16] J. G. Masek, F. E. Lindsay and S. N. Goward, "Dynamics of Urban Growth in the Washington D.C. Metropolitan Area, 1973-1996, from Landsat Observations,” International Journal of Remote Sensing, Vol. 21, No. 18, 2000, pp. 3473-3486. doi:10.1080/014311600750037507

[17] T. Fung, “An Assessment of TM Imagery for Land Cover Change Detection," IEEE Transactions on Geoscience and Remote Sensing, Vol. 28, No. 4, 1990, pp. 681-684. doi:10.1109/TGRS.1990.572980

[18] X. Chen, X. Li and J. Ma, "Urban Change Detection Based on Self-Organizing Feature Map Neural Network," Proceedings of the IEEE International Symposium on Geoscience and Remote Sensing, Vol. 5, 20-24 September 2004, pp. 3428-3431.

[19] P. Gamba, F. Dell'Acqua, "Increased Accuracy Multiband Urban Classification Using a Neuro-Fuzzy Classifier," International Journal of Remote Sensing, Vol. 24, No. 4, 2003, pp. 827-834.

[20] M. Stasolla and P. Gamba, "Exploiting Spatial Patterns For Informal Settlement Detection Inarid Environments Using Optical Spaceborne Data,” International Archives of Photogrammetry, Remote Sensing and Spatial Information Sciences, Vol. 36, 2007, pp.

[21] C. H. William, F. C. Williamand and K. Gyimah, "HighResolution Lidar-Based Landslide Hazard Mapping and Modeling, UCSF Parnassus Campus, San Francisco, USA," Bulletin of Engineering Geology and the Environment, Vol. 68, No. 2, 2009, pp. 263-276.

[22] V. Walter, "Object-Based Classification of Remote Sensing Data for Change Detection," ISPRS Journal of Photogrammetry and Remote Sensing, Vol. 58, No. 3-4, 2004, pp. 225-238.

[23] U. C. Benz, P. Hofmann, G. Willhauck, I. Lingenfelder, and M. Heynen, "Multi-Resolution, Object-Oriented Fuzzy Analysis of Remote Sensing Data for GIS-ready information," ISPRS Journal of Photogrammetry and Remote Sensing, Vol. 58, No. 3-4, January 2004, pp. 239-258.

[24] G. Sartori, G. Nembrini and F. Stauffer, "Monitoring of Urban Growth of Informal Settlements and Population Estimation from Aerial Photography and Satellite Imaging,” 2002. Occasional paper-thirstycitiesinwar.com.

[25] J. Abbott, "The Use of GIS in Informal Settlement Up- grading: Its Role and Impact on The Community and on Local Government," Habitat International, Vol. 27, No. 4, 2003, pp. 575-593. doi:10.1016/S0197-3975(03)00006-7

[26] A. Michel and B. Lortic, "Typologies Urbaines Et Télédétection Satellitaire: La Notion de Zones en Milieu Urbain,” Espace Géographique (FRA), Vol. 21, No. 2, 1992, pp. 167-178.

[27] T. Bauer and K. Steinccocher, "Per_Parcel Land Classification in Urban Areas Applying a Rule-Based Technique,” GeoBIT/GIS, Vol. 6, 2001, pp. 24-27.

[28] A. Puissant and C. Weber, "Démarche Orientée 'Objets-Attributs' et Classification D'images THRS," Revue Française de Photogrammétrie et De Télédétection, Vol. 173-174, 2004, pp. 123-134.

[29] M. Herold, M. Gardner, B. Hadley and D. Roberts, $2002 \mathrm{~b}$. "The Spectral Dimension in Urban Land Cover Mapping from High-Resolution Optical Remote Sensing Data," Proceedings of the 3rd Symposium on Remote Sensing of Urban Areas, June 2002, Istanbul, on CD Rom. http://www.lavieeco.com/news/economie/Bidonvillesenc ore-45-villes-a-traiter-d-ici-2012-17135.html (12/7/2010).

[30] C. J. Van Der Sande, S. M. De Jong, A. P. J. De Roo, “A Segmentation and Classification Approach of IKONOS-2 Imagery for Land-Cover Mapping to Assist Flood Risk and Flood Damage Assessment," International Journal of Applied Earth Observation and Geoinformation, Vol. 4. No. 3, 2003, pp. S217-S229. doi:10.1016/S0303-2434(03)00003-5

[31] R. A. A. Nobrega, C. G. O’Hara, J. A. Quintanilha, “Detecting Roads in Informal Settlements Surrounding, Saopaulo City by Using Object_Based Classification,” Proceedings of the 1st International Conference on $\mathrm{Ob}$ ject- Based Image Analysis, Salzburg, 2006, pp. .

[32] M. Baatz and A. Schäpe, "Multiresolution Segmentation -An Optimization Approach for High Quality MultiScale Image Segmentation,” Angewandte geographische Informationsverarbeitung XII: Beiträge zum AGIT-Symposium, Salzburg, 2000, pp. 12-23.

[33] J. Schieve, "Segmentation of High-Resolution Remotely Sensed Data-Concepts, Applications and Problems," Symposium on Geospatial Theory, Processings and Applications, Ottawa, 2002.

[34] T. Esch, A. Roth, S. Dech, "Robust Approach Towards an Automated Detection of Built-up Areas from High Resolution Radar Imagery," Proceedings of the ISPRS WG VII/1 "Human Settlements and Impact Analysis” 3rd International Symposium Remote Sensing and Data Fusion Over Urban Areas and the 5th International Symposium Remote Sensing of Urban Areas. Tempe, 14-16 March 2005.

[35] A. Karsenty, Antunes, B. A-F, Centeno, J-Silva. (2007) "Classification Orientée Objet de la Perméabilité des Sols en Zone Urbaine a L'aide D'imagerie Très Haute Résolution et de Données Laser Scanner à Curitiba (Brésil)” Anais XIII Simpósio Brasileiro de Sensoriamento Remoto, Florianópolis, INPE, p. 565-572

[36] E. Freauman, E. Wolf, "Segmentation of Very High Spa- 
tial Resolution Satellite Images in Urban Areas for Segments-Based Classification," Proceedings of the 3rd International Symposium Remote Sensing and Data Fusion Over Urban Areas, Tempe, 2005, pp. .

[37] L. Sparfel, F. Gourmelon and I. Le Berre, "Approch Orienté-Objet de L'occupation des Sols en Zone Cotière,” Revue Télédétection, Vol. 8, No. 4, 2008, pp. 237-256.

[38] G. Willhauck, “Comparison of Object Oriented Classification Techniques and Standard Image Analysis for the Use of Change Detection between SPOT Multispectral Satellite Images and Aerial Photos," International Archives of Photogrammetry and Remote Sensing, Vol. 33, 2000, pp. 214-221.

[39] R. Caloz and C. Collet, "Précis de Télédétection,” Traitements numériques d'images de télédétection, Presses de l’Université du Québec/AUPELF, Sainte Foy, Vol. 3,
2001.

[40] SDAU (2004) "Plan de développement stratégique et Schéma Directeur d'Aménagement urbain de la Wilaya du Grand Casablanca, Projet de diagnostic et Enjeux du développement, rapport $\mathrm{N}^{\circ} 3$.

[41] R. G. Congalton "Eview of Assessing the Accuracy of Classifications of Remotely Sensed Data," Remote Sensing of Environment, Vol. 37, 1991, pp. 35-46. doi:10.1016/0034-4257(91)90048-B

[42] R.-G. Conglaton and K. Green, "Assessing the Accuracu of Remotely Sensed Data: Principles and Practices," Lewis Publishers, New York, 1999.

[43] M. Aminipouri, “Objected-Oriented Analysis of very High Resolution Orthophotos for Estimating the Population of Slum Areas,” Case of Dar-Es-Salam, Tanzania, 2009. 